\title{
Current Information You Can Use
}

\section{Liner Shipping Conferences}

An Annotated Bibliography

Charles H.C. MacKenzie, Canadian National Marine,

Michael E. Power, Nova Scotia Bar, and Ted L. McDorman,

Dalhousie Ocean Studies Programme

Foreword by M.J. Shah

This bibliography will fill a large gap in shipping literature. The entries cover maritime law, international law and relations, economics, shipping, and commercial practice. The annotations concisely describe the contents of each work and will enable the reader to locate where various issues are discussed.

A Dalhousie Ocean Studies Programme Book.

160 pages $\quad$ ISBN 0-669-08660-6 $\$ 23.00$

\section{The Fish Feud}

\section{The U.S. and Canadian Boundary Dispute}

David L. VanderZwaag, Dalhousie Ocean Studies Programme

An investigation of and recommendation for settling U.S. disputes with Canada over fishing rights. VanderZwaag explores the argument from both sides and concludes with a proposal for future options that could well bring calm to the troubled waters.

160 pages ISBN 0-669-06611-7 \$22.00

\section{Maritime Boundary Delimitation} An Annotated Bibliography

Ted L. McDorman, Dalhousie Ocean Studies Programme, Kenneth P. Beauchamp, Canadian Arctic Resources Committee, and Douglas M. Johnston, Dalhousie Ocean Studies

Programme

This comprehensive bibliography includes the entire range of English-language books, monographs, and substantial articles published since World War II, as well as a selection of earlier works in English and recent works in French, German, Spanish, and Italian.

A Dalhousie Ocean Studies Programme Book

224 pages ISBN 0-669-06146-8 $\$ 25.00$

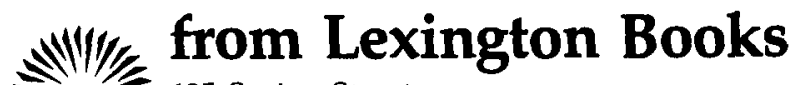

125 Spring Street

Lexington, MA 02173

(617) 862-6650 800-33-HEATH 